\title{
Water Retention and Saturation Degree of Peat Soil in Sebangau Catchment Area, Central Kalimantan
}

\author{
Akhmat Sajarwan $^{1}$, Adi Jaya ${ }^{1 *}$ and Irwan Sukri Banuwa ${ }^{2}$ \\ ${ }^{1}$ Faculty of Agriculture, University of Palangka Raya, Indonesia. ${ }^{2}$ Faculty of Agriculture, University of Lampung, \\ Indonesia.*e-mail: adijaya@agr.upr.ac.id
}

Received August 28, 2020; Revised November 27, 2020; Accepted 21 January 2021

\begin{abstract}
Water is an essential factor in forming, utilization, management, and sustainability of peat soil. This study was to obtain characteristics of water retention and porosity of peat soil. Peat samples were taken from the Natural Laboratory of Peat Forest, Central Kalimantan at shallow, medium, and deep peat at 0-50 cm (surface) and $50-100 \mathrm{~cm}$ (subsurface), while laboratory analyses carried out at Soil Laboratory, Universitas Gajahmada. The result shows that volumetric moisture content at the surface lower than subsurface, except for deep peat. The total pore for the surface was $84.67-86.98 \%$, while subsurface layers were $83.53-86.93 \%$. For surface layer, saturated degree $(S)$ medium peat higher than shallow and deep peat, while for shallow subsurface peat higher than medium and deep peat. $\mathrm{S}$ value all $\mathrm{pF}$ levels of surface for medium and deep peat higher than the subsurface. Bulk density for surface was $0.094 \mathrm{~g} \cdot \mathrm{cm}^{-3}\left(\rho_{\mathrm{b} \text { (wet) }}\right)$ and $0.22 \mathrm{~g} \cdot \mathrm{cm}^{-3}\left(\rho_{\mathrm{b} \text { (dry) }}\right)$ for shallow peat while medium peat are $0.084-0.087 \mathrm{~g} \cdot \mathrm{cm}^{-3}\left(\rho_{\mathrm{b} \text { (wet) }}\right)$ and $0.18-0.20 \mathrm{~g} \cdot \mathrm{cm}^{-3}\left(\rho_{\mathrm{b} \text { (dry })}\right)$, deep peat $0.064-0.090 \mathrm{~g} \cdot \mathrm{cm}^{-3}\left(\rho_{\mathrm{b} \text { (wet }}\right)$ and $0.11-0.16 \mathrm{~g} \cdot \mathrm{cm}^{-3}\left(\rho_{\mathrm{b}(\text { drv })}\right)$. For subsurface, bulk density of medium peat are $0.094-0.107 \mathrm{~g} \cdot \mathrm{cm}^{-3}\left(\rho_{\mathrm{b} \text { (wet }}\right)$ and $0.16-0.20 \mathrm{~g} \cdot \mathrm{cm}^{-3}\left(\rho_{\mathrm{b} \text { (ddry }}\right)$, deep peat are $0.067-0.090 \mathrm{~g} \cdot \mathrm{cm}^{-3}\left(\rho_{\mathrm{b} \text { (wet }}\right)$ and $0.10-0.17 \mathrm{~g} \cdot \mathrm{cm}^{-3}\left(\rho_{\mathrm{b} \text { (wet) }}\right)$. The particle density of surface and subsurface for shallow peat higher than medium and deep peat, with values $0.67-0.77 \mathrm{~g} . \mathrm{cm}^{3}, 0.61-0.66 \mathrm{~g} . \mathrm{cm}^{3}$, and $0.53-0.63 \mathrm{~g} . \mathrm{cm}^{3}$ for shallow, medium, and deep peat, respectively. Total pores for the surface layer decrease with increasing dry bulk density $(\mathrm{R}=0.624)$ and particle density $(\mathrm{R}=0.375)$. This fact seems to confirm a directly proportional relationship between parameters bulk and particle density with total pores.
\end{abstract}

Keywords: Moisture content of soil, peat land, saturation degree, soil porosity

\section{INTRODUCTION}

Water plays an essential role in forming, cultivation, utilization management, and sustainability of peat soil. Integrated water management is the key to restoring tropical peatland (Ritzema 1998; Sutikno et al.2020), in which diverse and contrasting requirements of the various types of land use need to be balanced. Water management to maintain levels optimal for distant land uses is crucial to achieving the wise use of tropical peatlands (Wösten and Ritzema 2001). Peatland was forming by the accumulation of organic material over a long time. The permanent waterlogging covered land surface caused the accumulation rate of organic material faster than their decomposition.

Most tropical peat is located at low altitudes where rain forest vegetation grows on a thick mass

J Trop Soils, Vol. 26, No. 1, 2021: 29-42

ISSN 0852-257X; E-ISSN 2086-6682 of mater there has accumulated over a thousand years to form deposits that are up to $20 \mathrm{~m}$ tick (Anderson 1983; Radjagukguk 1995; Page et al. 2006; Lampela et al. 2016). In the last two decades, some of the utilization and cultivated policy of tropical peatland, especially for peatland in Central Kalimantan, has been related to the water management aspect. Then, this policy caused many aspects of the peatland ecosystem have been damage, water release out of inland toward the area was accelerated, so while dry season, more layers of peat soil was extreme drying.

Therefore, to understand peatland's water release behavior, peat soil's water-holding capacity be understood as necessary. That is considered a macro scale for peatland water characteristics, and it depends on and is related to the water suction capacity of peat soil material. Moisture content was retained in peat soil material at various pressure levels, It could be explained by the suction capacity of peat soil material, and one of the determination 
was moisture contents measurement at some $\mathrm{pF}$ value level (soil moisture tension). It is defined as the logarithm of the absolute value of soil matric potential (Lal and Shukla 2004), which describes the work required to transfer reversibly and isothermally an infinitesimal amount of soil solution from a reservoir to the point of interest in the soil. That work to water transfer is considered as a force of water movement in the soil. In other words, the force that works is what causes the movement of water in the soil, commonly named water potential (y), and this water potential can be described as the value of $\mathrm{pF}$ curve. The peat matrix's capacity to retain and contain water depends on its several physical properties, particularly related to porosity availability. The water movement and moisture contents in the soil can be considered a function of gravimetrically and isothermally and influenced by several factors of soil properties, like structure, porosity, and another. (Weiss et al. 1998 and Walczak et al. 2002).

For the uncultivated area (natural condition) in the peatland field, the water movement has a crucial role in sustainability for its natural function. So, understanding peat soil's water tension characteristics is fundamental to get its wise management in the future. Water management, based on an understanding of peatland hydrology, is considered a prerequisite for the wise use of tropical peatland ecosystems (Muhammad and Rieley 2002; Rieley and Page 2005; Wösten et al. 2008). For this reason, a study was conducted in the intact tropical peatland Sebangau Catchment area, Central Kalimantan. This research aimed to determine the characteristics of water retention and saturation degree of peat soils from a different depth of peat.

\section{MATERIAL AND METHODS}

\section{Study Site}

The study was conducted in the Natural Laboratory of Peat Forest, Sebangau catchment areas, Central Kalimantan Province, as showed in Figure 1. Peat samples were taken from as many as 13 point locations, consist of namely shallow peat $(\mathrm{SP}=100 \mathrm{~cm})$ as many 1 locations; medium peat MP (100 - $200 \mathrm{~cm})$ as many 2 locations; and deep peat DP $(>200 \mathrm{~cm})$ as many 10 locations. At each sampling point, an undisturbed peat sample was taken using peat borers and a disturbed peat sample using ring samples with a diameter size $5.1 / 5.0 \mathrm{~cm}$ and $5.1 \mathrm{~cm}$ high. Peat samples were taken from peat layer of 0-50 cm dan $50-100 \mathrm{~cm}$ respectively, and that coded as SP L-1 (shallow peat $0-50 \mathrm{~cm}$ ), SP L-
2 (shallow peat $50-100 \mathrm{~cm}$ ), MP L-1 (medium peat 0-50 cm), MP L-2 (medium peat 50-100 cm), DP L1 (deep peat 0-50 cm), and DP L-2 (deep peat 50$100 \mathrm{~cm})$.

Determination of water retention was carried out the initiated method by Richards and Fireman (1943) and Richards (1947). Water retention measured at pressure $0.01 \mathrm{~atm}(\mathrm{pF} 1.0) ; 0.1 \mathrm{~atm}(\mathrm{pF}$ 2.0); 0.33 atm ( $\mathrm{pF} 2.54)$; and $15 \mathrm{~atm}$ ( $\mathrm{pF} 4.2$ ).

Besides, saturated peat samples were prepared to measure moisture content or equivalent to the pressure at $\mathrm{pF} 0$, bulk density determined by gravimetrically before undisturbed oven sample, namely wet or saturated bulk density, $\rho_{\mathrm{b}}$ (wet) and after oven undisturbed peat sample at $105 \mathrm{C}$ during 24 hours, namely dry bulk density, $\rho_{\mathrm{b}}($ dry) (Blake and Hartge 1986). Particle density (s) was measured using liquid pycnometers with water as filling liquid and water bath (Heiskanen 1992 and Redding et al. 2005), and the porosity is calculated from bulk density and particle density value (Hillel 1982).

\section{Analytical Procedures for Water Retention}

Peat samples to be analyzed are undisturbed in the ring sample. Pushed out the soil in the ring used to stick on one end, cut and taken a $1 \mathrm{~cm}$ thick from the other end, and then separated into four parts. Put each part of peat samples on the ceramic plate of $\mathrm{pF} 1.0 ; \mathrm{pF} 2.0$; and $\mathrm{pF} 2.54$, except peat sample for $\mathrm{pF} 4.2$ determination, was air-dried and sieved ( $2 \mathrm{~mm}$ mesh) and put on the ceramic plate also. Peat samples on the ceramic plate were saturated for 48 hours. Peat samples on a ceramic plate to determine $\mathrm{pF} 1.0, \mathrm{pF} 2.0$, and $\mathrm{pF}$ 2,54 were placed into pressure plate apparatuses, while $\mathrm{pF} 4.2$ placed into pressure membrane apparatus. Tightly closed the pans (pressure plate apparatus and pressure membrane apparatus) and switch on the compressor to provide pressure according to specified $\mathrm{pF}$. Take out the peat samples from pans after given pressure for 48 hours and then measure moisture content gravimetrically.

In this study, that meant of water retention is the amount of water that is retained in the peat matrix when it is being pressured or suction at a certain level (van Genuchten 1980; Walczak et al. 2002; Rajkai et al. 2004; Badv and Faridfard 2005; Kanzari et al. 2012; Jayakody et al. 2014; and Madi et al. 2018). The purpose of water retention measurement is to obtain a water retention curve, which can be obtained using various methods, such as that developed by van Genuchten 1980; Weiss 1998; Walczak et al. 2002; Rajkai et al. 2004; Badv and Faridfard 2005; Seki 2007; and Madi et al. 2018. 


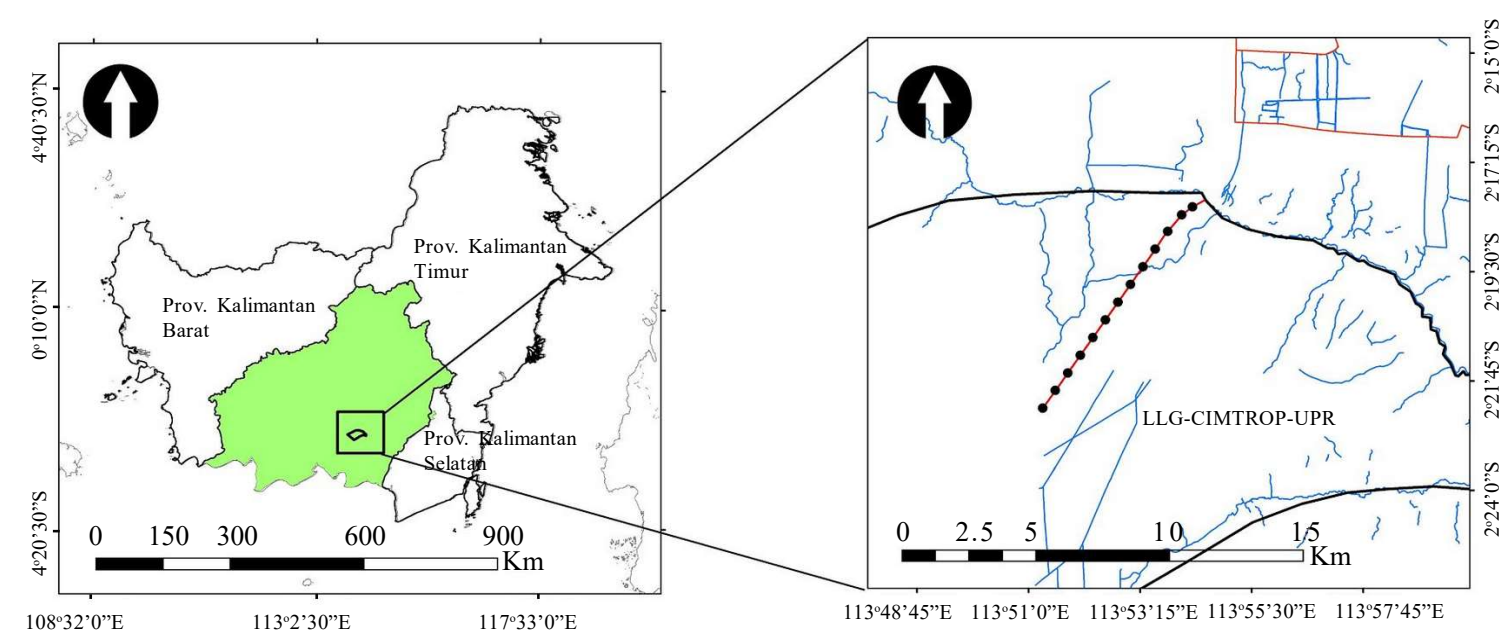

Figure 1. Location of research sites. $ح$ : Areal LLG_CIMTROP-UPR, : Observation plot

For this study, water retention curves were obtained using the method developed by van Genuchten (1980). In order to follow the procedure for making water retention curves or $\mathrm{pF}$ curve, according to van Genuchten (1980), three kinds of moisture content values are needed at each $\mathrm{pF}$ value, namely as follows:

\section{Measured Value of Water Retention}

Moisture contents were obtained directly from measured in the laboratory, defined as gravimetric moisture content, and converted to volumetric moisture contents value $\left(\mathrm{cm} \mathrm{cm}^{-3}\right)$ named as the measured value (Eq 1).

\section{Calculated Value of Water Retention}

The calculated value of moisture content was determined, followed van Genuchten equation:

$$
\theta v=\theta s+\frac{\theta \mathrm{s}-\theta \mathrm{r}}{\left.\left(1+(\alpha \psi)^{\mathrm{n}}\right)^{m}\right)}
$$

where:

$=$ Volumetric moisture contents

As $=$ saturated moisture contents

$\theta r \quad=$ residual moisture contents

$\psi \quad=$ potential matric $(\mathrm{h}=\mathrm{cm}$ water column $)$

$\alpha, \mathrm{n}, \mathrm{m}=$ empirical parameters by van Genuchten

The van Genuchten parameters, including the empirical parameters, were used in the SWRC fit program. This program can be executed directly from a web page (http://purl.org/net/swrc and Seki 2007). with the assumption that the value of $m$ parameter is $1-1 / \mathrm{n}$; soil moisture unit in $\mathrm{cm} \mathrm{cm}^{3}$; matric potential unit in $\mathrm{cm}$ (water column); the manual value of saturated soil moisture was fixed value at 0.900 ; the initial value of residual soil moisture was fixed value at 0.010 ; with positive value regression direction and fixed minimum value at 0.010 (Mualem 1976). After all of the van Genuchten parameters were obtained, the above equation's volumetric moisture contents can be calculated in the worksheet excel file using the excel solver function.

\section{Estimated Value of Water Retention}

In the worksheet excel file, the calculated value of volumetric moisture contents is shown in the regression line to get a regression with $\mathrm{R}^{2}$ value optimal (nearly value of 1 ). According to the equation getting in a worksheet, Excel can make an estimated value of volumetric moisture contents for more $\mathrm{pF}$ ranges.

\section{Bulk Density ( $\rho b)$ and Particle Density ( $\rho s$ ) Bulk Density ( $\rho b$ )}

Bulk density was determined by gravimetrical methods, mentioned in two different peat sample conditions, namely wet or saturation condition, symbolized as $\rho_{\mathrm{b}}$ (wet) and dry condition symbolized as $\rho_{\mathrm{b}}$ (dry) with a unit in $\mathrm{g} \mathrm{cm}^{3}$. Both bulk density values will be used to calculate the total pores $(\phi)$ and porosity $(\eta)$ values. The wet or saturated bulk density is the weight value of the wet peat sample (before oven), calculated by following equation 1a:

$$
\rho b_{(w e \lambda)}=\mathrm{WV} \text {. }
$$

Where :

$\rho b_{(w e \succsim)}=$ wet or saturated bulk density $\left(\mathrm{g} \mathrm{cm}^{-3}\right)$ 
$\mathrm{W}=$ weight of wet peat sample before oven $(\mathrm{g})$

$\mathrm{V}=$ volume of peat sample, considered to the volume of ring sample $\left(\mathrm{cm}^{3}\right)$

$$
\rho b_{(d r y)}=\frac{w}{v}
$$

Where :

$$
\begin{aligned}
\rho b_{(d r y)=} & \text { dry bulk density }\left(\mathrm{g} \mathrm{cm}^{-3}\right) \\
\mathrm{W} \quad & \text { weight of wet peat sample after oven at } \\
& \text { temperature } 105^{\circ} \mathrm{C}(\mathrm{g}) \text { during } 24 \mathrm{~h} . \\
\mathrm{V} \quad & \text { volume of peat sample, considered to the } \\
& \text { volume of ring sample }\left(\mathrm{cm}^{3}\right)
\end{aligned}
$$

\section{Particle Density ( $\rho S$ )}

Particle density (s) was measured using liquid pycnometers with water as filling liquid and water bath (Heiskanen 1992 and Redding et al. 2005), calculated following equation:

$$
\rho S=\frac{[100 x(\mathrm{~B}-\mathrm{A})]}{(100+\theta) x(V w 2-V w 1-V w 3)}
$$

where:

$$
\rho S=\text { Particle density }\left(\mathrm{g} \mathrm{cm}^{3}\right)
$$

$\mathrm{B}=$ weight of pycnometer whit containing peat sample which $2 \mathrm{~mm}$ sieve pass (g)

$\mathrm{A}=$ weight of pycnometer $(\mathrm{g})$

$\theta=$ moistures content of peat sample (\%)

$$
\mathrm{V}_{\mathrm{w} 1}=\frac{[C-B]}{\rho_{w_{1}}}
$$

where:

$\mathrm{V}_{\mathrm{w} 1}$ = water volume for water-specific density (g.cm3) at a pycnometer temperature after filled by water and peat sample $\left(\mathrm{cm}^{3}\right)$.

$\mathrm{C}=$ weight of pycnometer containing peat sample and water $(\mathrm{g})$

$\mathrm{B}=$ weight of pycnometer containing peat sample (g)

$\rho_{w_{1}}=$ Specific density of water at a temperature in pycnometer after filled by water $(\mathrm{g} \mathrm{cm}$ $\left.{ }^{3}\right)$.

$$
\mathrm{V}_{\mathrm{w} 2}=\frac{[D-A]}{\rho_{w_{2}}}
$$

where:

Vw2 = water volume for water-specific density (g $\mathrm{cm}^{-3}$ ) at a pycnometer temperature was filled by certain water only.

$\mathrm{D}$ = weight of pycnometer was filled by certain water only $(\mathrm{g})$

A = weight of pycnometer $(\mathrm{g})$ $\rho_{w_{2}}=$ Specific water density at a temperature in pycnometer after filled by water only (g.cm3).

$$
\mathrm{V}_{\mathrm{w} 3}=\frac{[\theta(B-A)]}{\left[(100+\theta) x \rho_{w_{3}}\right.}
$$

where:

Vw3 = volume of water for water-specific density (g.cm3) at temperature $60{ }^{\circ} \mathrm{C}$.

$\mathrm{B}=$ weight of pycnometer containing peat sample (g)

$\mathrm{A}=$ weight of pycnometer $(\mathrm{g})$

$\theta=$ moistures content of peat sample (\%)

$\rho_{w_{3}}=$ Specific density of water at temperature 60 ${ }^{\circ} \mathrm{C}\left(\mathrm{g} \mathrm{cm}^{3}\right)$.

\section{Porosity}

Porosity value was determined as total pore (mentioned in \% value) and porosity, calculated by the following equation (Ninmo 2004) :

$$
\Phi=\left(1-\left(\rho b_{(\text {wet })} / \rho s\right)\right) \times 100 \%
$$

where :

$$
\begin{aligned}
\Phi \quad= & \text { pore total (\%) } \\
\rho b_{(\text {wet })}= & \text { saturated bulk density, mentioned in } \mathrm{g} \mathrm{cm}^{-3} \\
& \quad \text { (see equation 2a); } \\
\rho S \quad= & \text { specific density or particle density }\left(\mathrm{g} \mathrm{cm}^{-3}\right) \\
& \quad \text { (see equation 3) }
\end{aligned}
$$

\section{Moisture Volumetric}

Moisture volumetric calculated by following equation (Wiess et al. 1998) :

$$
\theta_{v}=\theta_{m} x \frac{\rho_{b(d r y)}}{\rho_{w}}
$$

where :

$\theta_{v}=$ moisture volumetric $(\% \mathrm{v})$

$\theta_{m}=$ moisture gravimetric $\left(\% \mathrm{w}=\mathrm{g} \mathrm{g}^{-1}\right)$

$$
\theta_{m}=\frac{m_{w}}{m_{s d}}:
$$

where :

$m_{w} \quad=$ mass of water (water loss after the oven, at $\mathrm{T}=105^{\circ} \mathrm{C}$ during $24 \mathrm{~h}$ )

$m_{s d}=$ mass of dry soil (after oven at $\mathrm{T}=105^{\circ} \mathrm{C}$ during $24 \mathrm{~h}$ )

$\rho_{b(d r y)}=$ dry bulk density mentioned in $\mathrm{g} \mathrm{cm}^{-3}$

$\rho_{w} \quad=$ water particle density $\left(\mathrm{g} \mathrm{cm}^{-3}\right)$ 


\section{Pores Saturation}

Saturated degree, namely as water retention, calculated using the following equation (Walker $e t$ al. 1931):

$$
S=(\theta / \eta) 100
$$

where :

$$
\begin{aligned}
\mathrm{S} & =\text { saturated degree }(\% \mathrm{v}) \\
\theta & =\text { moisture volumetric }(\% \mathrm{v}) \text { at each certain } \mathrm{pF} \\
& \text { value } \\
\eta \quad & \text { porosity }(\%)
\end{aligned}
$$

\section{RESULTS AND DISCUSSION}

\section{Water Retention}

\section{Measured Value}

Table 1 shows that volumetric moisture content $\left(\theta_{\mathrm{w}}\right)$ at the surface layer $(0-50 \mathrm{~cm})$ is always lower than subsurface layer $(50-100 \mathrm{~cm})$, except from deep peat categories, where for the level of $\mathrm{pF} 1$, $\mathrm{pF} 2$, and $\mathrm{pF} 2,54$, the $\theta_{\mathrm{w}}$ at a surface layer higher than a subsurface layer. Moisture contents for deep peat sample, at the surface layer, were $29.36 \%$, $17.59 \%$, and $13.37 \%$, respectively for the level of $\mathrm{pF} 1, \mathrm{pF} 2$, and $\mathrm{pF} 2.54$, lower than the subsurface layer, which each has $36.77 \%, 18.90 \%$ and 14.51 $\%$ moisture contents respectively. The results because water movement in the surface layer is more dynamic than in the subsurface layer (Kutilek and Novak 1998). However, almost all of them, shallow peat moisture contents at the same $\mathrm{pF}$ value, are commonly higher than medium peat and deep peat. As mentioned above, that on the shallow peat, there might have more micropores, while the medium peat and peat were more macropores (Nimno 2004).

As mentioned previously, shallow peat in this study is located at about $1 \mathrm{~km}$ from the Sebangau river's edge, just behind and even including the levee area. The accumulation rate of peat material in shallow peat zones runs very slowly and even for the current decade as if deemed to have stopped. Pedogenesis dynamics on these zones are not significantly accelerated to the peat material accumulation. Regarding this study's focus, the important thing that concerns the influence of the peat layer's proximity with the mineral layer below and the presence of sedimentary minerals in the peat matrix to water-retaining capacity. On the other hand, for medium peat and deep peat sample, they have been taken from around and including peat dome area, it is estimated to have a more porous physical structure than shallow peat. It is thought to be the reason why its ability to retain water is lower than shallow peat.

\section{Calculated Value}

Data of measured value used to obtain the calculated value of volumetric moisture contents after divided 100 (convert from percent volumetric value). Furthermore, I entered these data as input data on the SWRC software program (version 3) and then computed them to obtain the van genuchten empirical parameters. The computation result is shown in Table 2.

Based on data shown in Table 2, doing calculation volumetric moisture contents value $(\theta)$ by input data to van Genuchten equation (eq.1). In equation number 1 before, a water potential parameter ( $\mathrm{pF}$ value) is converted to a high value of centimeters $(\mathrm{cm})$ of the water column, in its equation symboled $(\boldsymbol{\Psi})$. For example, after input data of these the parameters $(\alpha, n$, and $m)$ to equation (1), is $\left.\left.\theta=1+(\alpha \Psi)^{\wedge} \mathrm{n}\right)^{\wedge} \mathrm{m}\right)$, the value of $(\theta)$ for curve 1 (SP L-1) at $\mathrm{pF} 0, \mathrm{pF} 1$ and $\mathrm{pF} 2$ are $0.798 ; 0.747$; and 0.250 respectively. This computation is mentioned as $\theta$ value before solved

\begin{tabular}{|c|c|c|c|c|c|c|c|c|c|c|c|c|}
\hline \multirow{3}{*}{$\begin{array}{c}\mathrm{pF} \\
\text { level }\end{array}$} & \multicolumn{4}{|c|}{ SP } & \multicolumn{4}{|c|}{ MP } & \multicolumn{4}{|c|}{ DP } \\
\hline & \multicolumn{2}{|c|}{$0-50 \mathrm{~cm}$} & \multicolumn{2}{|c|}{$50-100 \mathrm{~cm}$} & \multicolumn{2}{|c|}{$0-50 \mathrm{~cm}$} & \multicolumn{2}{|c|}{$50-100 \mathrm{~cm}$} & \multicolumn{2}{|c|}{$0-50 \mathrm{~cm}$} & \multicolumn{2}{|c|}{$50-100 \mathrm{~cm}$} \\
\hline & $\mathrm{V}$ & $\%$ & $\mathrm{~V}$ & $\%$ & $\mathrm{v}$ & $\%$ & $\mathrm{v}$ & $\%$ & $\mathrm{v}$ & $\%$ & $\mathrm{v}$ & $\%$ \\
\hline 0 & 0.798 & 79.83 & 0.816 & 81.62 & 0.857 & 85.68 & 0.827 & 82.73 & 0.823 & 82.26 & 0.817 & 81.72 \\
\hline 1 & 0.789 & 78.88 & 0.803 & 80.33 & 0.832 & 83.23 & 0.807 & 80.69 & 0.804 & 80.36 & 0.808 & 80.77 \\
\hline 2 & 0.253 & 25.32 & 0.309 & 30.86 & 0.346 & 34.55 & 0.276 & 27.64 & 0.326 & 32.59 & 0.299 & 29.89 \\
\hline 2.54 & 0.207 & 20.72 & 0.269 & 26.89 & 0.325 & 32.45 & 0.256 & 25.64 & 0.294 & 29.37 & 0.275 & 27.51 \\
\hline 4.2 & 0.189 & 18.92 & 0.224 & 22.43 & 0.092 & 9.18 & 0.082 & 8.23 & 0.066 & 6.55 & 0.061 & 6.14 \\
\hline
\end{tabular}
because that changes after the excel solver function have been done. Furthermore, using the solver function in the worksheet excel program to obtain

Table 1 . The measured value of moisture contents $\left(\theta_{\mathrm{v}}\right.$ in $\left.\% \mathrm{v}\right)$. 
Table 2. Van Genuchten parameters value (empirical parameter by SWRC program version 3).

\begin{tabular}{lccccc}
\hline \multirow{2}{*}{ Curve/sample } & \multicolumn{5}{c}{ Van Genuchten parameters value } \\
\cline { 2 - 6 } & $\theta_{\mathrm{r}}$ & $\alpha$ & $n$ & $\theta_{\mathrm{s}}$ & $m$ \\
\hline 1/SP L-1 & 0.195 & 0.0312 & 3.0282 & 0.799 & 0.6698 \\
2/SP L-2 & 0.240 & 0.0346 & 2.6417 & 0.820 & 0.6215 \\
3/MP L-1 & 0.092 & 0.0529 & 1.5356 & 0.879 & 0.3488 \\
4/MP L-2 & 0.110 & 0.0452 & 1.8137 & 0.847 & 0.4486 \\
5/DP L-1 & 0.065 & 0.0504 & 1.5392 & 0.846 & 0.3503 \\
6/DP L-2 & 0.075 & 0.0467 & 1.6346 & 0.842 & 0.3882 \\
\hline
\end{tabular}

the $\theta$ value after solved. The value of $\theta$ (before and after solved) computation by excel solver function is shown in Table 3.

The value of $\theta$ after solved was obtained by following completely and appropriately the procedures in excel solver dialog, were filled the cell target dialog with the value of van Genuchten parameter $\left(\alpha, \mathrm{n}\right.$, and $\left.\theta_{\mathrm{r}}\right)$, which will be changed to fitting water retention curve. One of its procedures is optimizing the squared difference at the minimum value and different (diff.) value, which is mentioned as distinct $(\theta)$ between a measured value and calculated value before it is solved. Based on the calculating result in the excel solver procedure, an estimated value of $(\theta)$ can be obtained at more points of $\mathrm{pF}$ ranges. The estimated value makes fitting water retention $(\mathrm{pF})$ curve, as shown in Figures 2 and 3 . In this paper, as many as six curves could be made. Naming curve 1 , curve 2 , and so on until curve 6 is actually the name for the sample code tested, namely curve 1 for SP L-1, curve 2 for SP L-2, curve 3 for MP L-1, curve 4 for MP L-2, curve 5 for DP L-1 and finally curve 6 for DP L-2. This water retention curve is a curve form after fitting has been used the SWRC program and excel solver function.

According to Figure 2, volumetric moisture contents' changes follow the same pattern for all peat sample categories, but the SP has a more apparent pattern than MP and DP. For the SP sample, the estimated value of volumetric moisture content is more approach to the measured value, while for the MP and DP sample categories, it has weak proximity to the measured value. The decreasing volumetric moisture content following an increasing $\mathrm{pF}$ value for SP more confirm the curve $\mathrm{pF}$ pictures by many other types of research, particularly with the water retention study in mineral soil (Rajkai et al. 2004; and Vernay et al. 2016). The SP can represent the peat soil in hemic decomposition stages, which is more penetrated by fine mineral material (Widjaya-Adhi 1992). The MP and DP, which have lowes stages of decomposition, mentioned fabric material, which is undoubtedly formed by more large fraction material than the SP sample. Perhaps this case is because the pattern of water retention changes is difficult to define, where proximity estimated value line with measured value is more weakness than SP categories.

Volumetric moisture content tends to decrease when the water potential is increasing. That most significant change happened between $\mathrm{pF} 1$ to $\mathrm{pF} 2$ and $\mathrm{pF} 2.54$ to $\mathrm{pF} 4.2$, but almost unchanged between $\mathrm{pF} 0$ to $\mathrm{pF} 1$ and $\mathrm{pF} 2$ to $\mathrm{pF} 2.5$. However, it is related to the pores size distribution of the peat matrix. The same trend happened for volumetric moisture contents at the surface layer $(0-50 \mathrm{~cm})$ and subsurface layer $(50-100 \mathrm{~cm})$. In general, water retention curves' appearance is similar to the other studies (Walczak et al. 2002; Campos et al. 2011; Indahyani et al. 2017; and Madi et al. 2018). Volumetric moisture contents slowly decreased at low $\mathrm{pF}$ value ( $\mathrm{pF} 0$ to $\mathrm{pF} 1)$ and high $\mathrm{pF}$ value $(\mathrm{pF}$ 2.54 to $\mathrm{pF} 4.2$ ), but its rapid decrease from $\mathrm{pF} 1$ to

Table 3. Calculated value of $\theta$ (before and after solved) computation by excel solver function

\begin{tabular}{cccccccccccccc}
\hline $\mathrm{pF}$ & \multicolumn{2}{c}{ Curve 1 } & \multicolumn{2}{c}{ Curve 2 } & \multicolumn{2}{c}{ Curve 3 } & \multicolumn{2}{c}{ Curve 4 } & \multicolumn{2}{c}{ Curve 5 } & \multicolumn{2}{c}{ Curve 6 } \\
\cline { 2 - 13 } value & Before & After & Before & After & Before & After & Before & After & Before & After & Before & After \\
\hline 0 & 79.85 & 79.90 & 81.77 & 81.99 & 74.40 & 86.90 & 79.21 & 84.44 & 71.60 & 83.65 & 74.60 & 83.60 \\
1 & 74.70 & 78.78 & 73.36 & 80.04 & 55.20 & 78.24 & 59.36 & 77.97 & 52.68 & 75.37 & 54.94 & 76.03 \\
2 & 24.96 & 25.38 & 30.69 & 31.13 & 32.07 & 41.40 & 27.70 & 31.21 & 29.53 & 39.11 & 28.46 & 35.80 \\
2.54 & 20.08 & 19.93 & 25.12 & 24.80 & 23.45 & 24.30 & 18.59 & 17.56 & 20.83 & 21.77 & 19.26 & 19.02 \\
4.2 & 19.50 & 19.65 & 24.00 & 24.27 & 11.28 & 12.45 & 11.35 & 13.41 & 8.57 & 9.56 & 8.64 & 10.27 \\
\hline
\end{tabular}



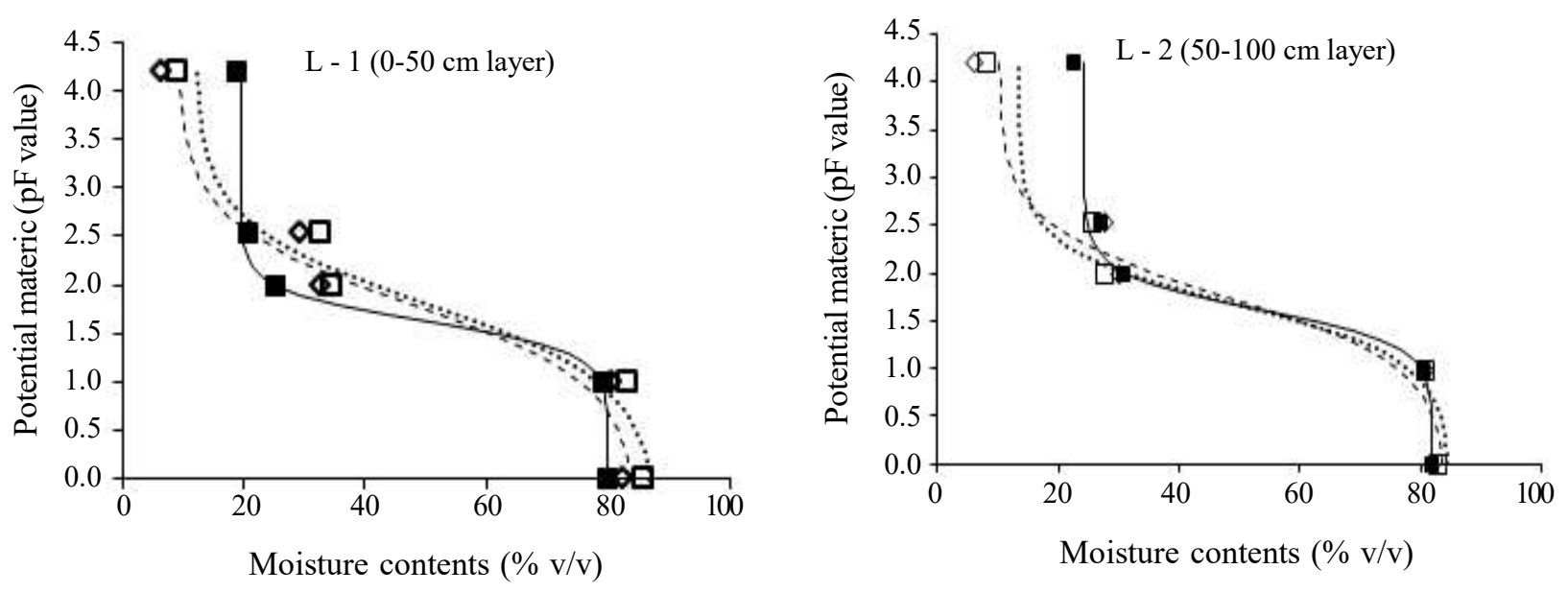

Figure 2. Water retention curve for surface layer peat sample. $\mathbf{a}$ : SP measured, $\mathbf{0}:$ MP measured, $\bullet:$ DP measured, $\longrightarrow$ : SP estimated, ........ : MP estimated, - - - - : DP estimated.

pF 2. The hydrological characteristics of soils, such as water retention and the water movement rate, depend primarily on the material's total porosity and pore-size distribution (Kutilek and Novak 1998). The soil water potential-moisture characteristics allow the calculation of effective pore size distribution.

Water retention curves make it possible to determine the amount of strongly bound water $(\mathrm{pF}$ higher than 4.2), which indicates the presence of micropores in soil. The volume of mesopores can be calculated as a difference between water content at $\mathrm{pF} 2$ and 4.2. The soil's mesopore content corresponds to the water content available for plants, and the water content at $\mathrm{pF} 2.0-2.7$ and $2.7-4.2$ represents readily available and poorly available water, respectively. The water content between saturation and $\mathrm{pF} 2$ indicates the presence of macropores. In macropores, a rapid gravitational efflux of water takes place. It is called soil aeration capacity. Water capacity between $\mathrm{pF} 2.0$ and 4.2 is potentially good retention, but water is unavailable for plants at the up of pF 4.2 (Okruszko 1993).

The peat matrix's volumetric moisture matrix has the same trend for three-peat thickness categories; were shallow peat, medium peat, and deep peat. Shallow peat moisture levels always appear to be higher than medium peat and deep peat, and this occurs both for the top surface peat layer $(0-50 \mathrm{~cm})$ and for the subsurface peat layer $(50-$ $100 \mathrm{~cm})$. The results may be related to soil mineral materials' solubility in the peat matrix, which is supported by a peat layer that coincides with the mineral layer in the ground. Essential on some of the peat characteristic studied in the tropical peatland of Sabangau catchment area, the mineral soil material under the peat layer is generally in the form of clay mineral material with a fraction size of $<2$ ìm or amorphic fraction of peat material, which varies of 0.04 to $0.11 \mathrm{~g} . \mathrm{cm}^{3}$ (Könönen et al. 2015), and its solubility can fill the peat matrix pore space. The existence of the clay fraction in the peat matrix determines the structure of the pore space, where micropores dominate the more fine fractions $(<2$ ìm), including clay minerals, the pores space in the peat matrix.

For all peat thickness categories and separate peat layer, the volumetric moisture content as a measured value at $\mathrm{pF} 4,2$ is remaining about $20 \%$ volume of pore space (except SP L-2, which have $\mathrm{q}=22.30 \% \mathrm{v}$ ); while at the $\mathrm{pF} 0$ is maximum about $85.86 \%$ by volume (Table 2 and 3 ). The first phenomena show that when there is a driving force to release water from the peat matrix equal ( $\mathrm{pF} 4.2$ ), less than $20 \%$ of the pore space volume still filled water. The two phenomena show that when the power of water release from the peat matrix is equal to pressure nearly $\mathrm{pF} 0$ (in a flooded field) or saturated, a maximum of $86 \%$ of the volume of the pore space is filled by water, or about $14 \%$ volume of pore space is filled by air as a void pore.

For the first phenomena, explained at $\mathrm{pF}$ e" 4.2 , the plant's root can not take that water, so it is often referred to as the permanent wilting point. Based on the soil pore function, the pore filled with water at that $\mathrm{pF}$ d" 4,2 level has namely pored for available water, where accorded water release from the soil matrix naturally. The value of about $20 \%$ pore volume still containing water for this study was lower than the percent volume value of water at the same $\mathrm{pF}$ level for mineral soil. For the second phenomenon, a maximum of $86 \%$ of the pore volume contains water, even though it is a saturated condition (in a flooded field). In other words, there is always an empty pore, filled with air or vacuum. Van 
Genuchten and Wierenga (1976) have grouped pores into " 2 regions", namely "mobile region" and "immobile region." For the pores, including the "mobile region" group, water and soil solutions are relatively more accessible, but the "immobile region" is relatively more complex. The water and soil solution movement occur only through the diffusion mechanism, and the potential water that works is the osmotic potential.

\section{Porosity and Volumetric Moisture Content}

The total pore for surface layer is $84.67 \%$; $86.40 \%$ (average); and $86.98 \%$ (average) for SP, MP and DP categories respectively. The total pores' value for the subsurface layer is $83.53 \%$, $84.56 \%$ (average), and $86.93 \%$ (average) for SP, MP, and DP categories. The data shows that most of the volume of soil is pore space. Furthermore, not all pore spaces can be filled with water, and the maximum volume of the pore that can be filled by water is called saturated volume or known as volumetric moisture content. The value of volumetric moisture contents calculated following equation 5 above, and its result calculated in Table 1.

Additionally, in the van Genuchten Models, several volumetric moisture content parameters were used, namely saturated moisture contents $\left(\theta_{\mathrm{s}}\right)$ and residual moisture contents $\left(\theta_{\mathrm{r}}\right)$. The saturated moisture contents $\left(\theta_{\mathrm{s}}\right)$ which are equivalent to porosity $\left(\eta=V_{\mathrm{v}} / V\right.$; where $\mathrm{V}_{\mathrm{v}}=$ void volume $\cong$ total pore $(\phi)$; and $\mathrm{V}$ is the volume of soil sample), and the residual moisture contents $\left(\theta_{\mathrm{r}}\right)$ is the residual water content, defined as the water content for which the gradient $\mathrm{d} \theta / \mathrm{dh}$ becomes zero. In addition, the term pore saturation degree is also known. Based on available data, and that may be calculated, some porosity parameters are obtained, as shown in Table 4.

The data presented in Table 4 illustrates the characteristics of peat soils' porosity, which are only data on a laboratory scale, which cannot necessarily explain the field's actual situation. However, the data obtained is still within the range of normal values commonly found by researchers. The value of pores total $(\phi)$ are ranges from $0.84(83.53 \%)$ to 0.87 $(86.98 \%)$ and the porosity $(\eta)$ are ranges from 0.83 (83.45\%) to $0.87(86.90 \%)$. According to Radforh et al. (1977) in Letts et al. (2000), the average value of peat porosity ranges from 0.81 to 0.95 , greater in fibric peat than in sapric peat. Porosity from deep peat (DP) area is greater than shallow (SP) and medium-deep (MP). As mentioned in the text data shown in Table 6 interpretation, the peat decomposition stages' level is fibric, determined based on measured bulk density data. The surface layer and subsurface layer's difference porosity is not significant, less than 1 value or 2 in percent.

The solid fraction volume (less than 20\%) in the ranges from $13.11 \%$ to $16.56 \%$ means less than one-third of the peat matrix in the form of solids material. For fibric peat, almost organic material is a significant fraction, so the matrix structure and arrangement are porous and easily disturbed. One of the parameters related to porosity behavior reported in table 4 is pores value (e), ranging from 5.04 to 6.63 . The value obtained is slightly lower than the (e) value reported by Johari et al. (2016) for peat soil from Parit Nipah Darat. The value of pores (e) or often mentioned as a void ratio, is defined as a (volumetric) ratio of the volume of void space (fluid and air together) $\left(\mathrm{V}_{\mathrm{v}}\right)$ and volume of solids $(\mathrm{V})$. The value of the void ratio depends on soils' volumetric changes (the void ratio of loose soils is higher than that of dense soils).

\section{Saturated Degree (S)}

Vv's value ranges from $83.53 \%$ to $86.98 \%$, highest for deep peat compared to shallow and medium peat. The deep peat material, which has fibric stages decomposition, might consist of high organic material, with a large fraction, so pores structure formed is dominated by macropores and mesopores (Ninmo 2004; Rezanezhad et al. 2009; Rezanezhad et al. 2010). The pores' void space can be broken down into two-phase volumes, i.e., saturation phase and the unsaturation phase (volume of air). For a sample of DP L-1 and DP L-2, it has a void volume $\left(\mathrm{V}_{\mathrm{v}}\right)$ value of about $86.93 \%$ and $86.96 \%$, respectively, was consist of saturation pores (S) portion and air pores portion $\left(\mathrm{V}_{\mathrm{z}}\right)$. The value of (S), from DP L-1, for example, has (S) value about $94.57 \%$; $92.39 \% ; 37.47 \% ; 33.77 \%$; and $7.53 \%$ at different of water potential ( $\mathrm{pF}$ value) are $\mathrm{pF} 0 ; \mathrm{pF}$ $1 ; \mathrm{pF} 2 ; \mathrm{pF} 2.54$ and $\mathrm{pF} 4.2$, respectively.

Table 5 show that for almost all $\mathrm{pF}$ level in the surface layer (L-1), the value of $S$ for MP tends to higher than SP and DP, except for $\mathrm{pF} 4.20$, the SP $(22.35 \%)$ has higher than MP $(10.63 \%)$ and DP $(7.53 \%)$. For the subsurface layer (L-2), the value of S for SP tends to higher than MP and DP, except for $\mathrm{pF} 0$, the MP has higher than SP and DP. Another phenomenon found was that the $S$ value for all $\mathrm{pF}$ levels in the surface layer (L-1) for MP and DP categories tended to be higher than the $S$ Value for the subsurface layer (L-2). Unlike what happened for SP, the S value for the subsurface layer (L-2) tended to be higher than for the surface layer (L- 
1). Based on these data, it can be concluded that the $S$ value tends to decrease with the deeper peat layer. It is related to the movement of water in a saturated atmosphere, both vertically and horizontally on peat soils, which according to Beckwith et al. (2003a) in Rezanezhad et al. (2012), the $\mathrm{K}$ value (saturated hydraulic conductivity) generally decreases downward into the peat layer.

The saturated degree is the proportion of volumetric moisture contents on porosity. The saturated degree at the surface layer is not significantly different from the subsurface layer for all peat thickness categories. The changes of saturated degree have the same pattern with volumetric moisture content changes in its relation with the porosity characteristic, e.g., size, distribution, structure, and interconnection or continuously (Quinton et al. 2008; Quinton et al. 2009; Rezanezhad et al. 2010). The most likely main factor that affected the saturated degree appearance is the type of material texture forming the peat matrix (Rezanezhad et al. 2012 and 2016).

The relation between bulk and particle density with porosity

The parameters of bulk density, particle density, and porosity are presented in Table 6 .

\section{Bulk Density}

The value of $\rho_{\mathrm{b}(\text { wet })}$ for shallow peat samples is $0.094{\mathrm{~g} . \mathrm{cm}^{-3}}^{-3}$ lower than $0.22 \mathrm{~g} . \mathrm{cm}^{-3}$ of $\rho_{\mathrm{b} \text { (dry })}$, and that trend was followed by its for medium peat and deep peat categories. For the surface layer, values bulk density of medium peat are ranges of 0.084 $0.087 \mathrm{~g} . \mathrm{cm}^{-3}\left(\rho_{\mathrm{b}(\text { wet })}\right)$ and $0.18-0.20 \mathrm{~g} . \mathrm{cm}^{-3}$ $\left(\rho_{\mathrm{b} \text { (dry })}\right)$. While for deep peat are ranges $0.064-0.090$ g.cm ${ }^{-3}\left(\rho_{\mathrm{b}(\text { wet }}\right)$ and $0.11-0.16$ g.cm $\mathrm{cm}^{-3}\left(\rho_{\mathrm{b}(d r y)}\right)$. For the subsurface layer, values bulk density for sample of medium peat are ranges of $0.094-0.107{\mathrm{~g} . \mathrm{cm}^{-3}}^{-3}$ $\left(\rho_{\mathrm{b}(\text { wet })}\right)$ and $0.16-0.20 \mathrm{g.cm}{ }^{-3}\left(\rho_{\mathrm{b}(d r y)}\right)$. While for deep peat are ranges of $0.067-0.090 \mathrm{~g}^{-\mathrm{cm}^{-3}}\left(\rho_{\mathrm{b} \text { (wet })}\right)$ and $0.10-0.17 \mathrm{~g} . \mathrm{cm}^{-3}\left(\rho_{\mathrm{b}(\text { wet })}\right)$. The dry bulk density always higher than in wet conditions. That is related to the phenomena of water release from the peat matrix, followed by the shrinking of peat volume and contents of the fine fraction of the peat matrix and porosity (Boelter 1965). When peat materials are dried, their volume is reduced considerably caused by shrinkage events. Therefore, bulk density must be calculated based on the wet bulk volume to represent field conditions. If bulk densities are measured using a reduced volume, they will be too high, and volumetric water contents calculated with these values will also be too high. Some reports show bulk density and water contents (oven- dry weight 
Table 5. Saturated degree (\%) of peat sample at some $\mathrm{pF}$ level.

\begin{tabular}{lcccccc}
\hline \multirow{2}{*}{$\begin{array}{c}\text { Level of pF } \\
\text { value }\end{array}$} & \multicolumn{2}{c}{ Shallow Peat } & \multicolumn{2}{c}{ Medium Peat } & \multicolumn{2}{c}{ Deep Peat } \\
\cline { 2 - 6 } & $\begin{array}{c}\mathrm{L}-1 \\
(0-50 \mathrm{~cm})\end{array}$ & $\begin{array}{c}\text { L-2 } \\
(50-100 \mathrm{~cm})\end{array}$ & $\begin{array}{c}\mathrm{L}-1 \\
(0-50 \mathrm{~cm})\end{array}$ & $\begin{array}{c}\text { L-2 } \\
(50-100 \mathrm{~cm})\end{array}$ & $\begin{array}{c}\text { L-1 } \\
(0-50 \mathrm{~cm})\end{array}$ & $\begin{array}{c}\text { L-2 } \\
(50-100 \mathrm{~cm})\end{array}$ \\
\hline pF 0 & 94.28 & 97.71 & 99.17 & 97.84 & 94.57 & 94.01 \\
pF 1 & 93.16 & 96.17 & 96.33 & 95.42 & 92.39 & 92.91 \\
pF 2 & 29.90 & 36.94 & 39.99 & 32.69 & 37.47 & 34.38 \\
pF 2.54 & 24.47 & 32.19 & 37.56 & 30.32 & 33.77 & 31.65 \\
pF 4.20 & 22.35 & 26.85 & 10.63 & 9.73 & 7.53 & 7.06 \\
\hline
\end{tabular}

basis) that result in volumetric water contents well over 100 percent (Boelter 1965).

Peat material from deep peat (DP) area, commonly have dry bulk density were lowes than $0.15 \mathrm{~g} . \mathrm{cm}^{-3}$, except for DP-6 $\left(\rho_{\mathrm{b}(d r y)}=0.16 \mathrm{~g} \mathrm{~cm}^{-3}\right)$. That is considered as fabric categories of decomposition degree. Peat material from shallow peat (SP) and medium peat (DP) area were have dry bulk density $0.22 \mathrm{~g} \mathrm{~cm}^{-3}$ (SP-1); $0.18 \mathrm{~g} \mathrm{~cm}^{-3}$ (MP-1) and $0.20 \mathrm{~g} \mathrm{~cm}^{-3}(\mathrm{MP}-2)$, respectively. That is considered hemic categories of decomposition level (Widjaya-Adhi 1992), and their structures of peat matrix structures are not dominated by the fine or coarse fraction.

\section{Particle Density}

Based on data shown in Table 6, the value of particle density $\left(\rho_{s}\right)$ in the surface layer (L-1) and subsurface layer (L-2) for SP categories consistently higher than the MP and DP categories, where the SP categories have values $0.67 \mathrm{~g} \mathrm{~cm}^{3}$ and 0.77 g. $\mathrm{cm}^{3}$; for the MP categories has values range from $0.61 \mathrm{~g} \mathrm{~cm}^{3}$ to $0.66 \mathrm{~g} \mathrm{~cm}^{3}$; and for the DP categories has values range from $0.53 \mathrm{~g} \mathrm{~cm}^{3}$ to $0.63 \mathrm{~g} \mathrm{~cm}^{3}$. The occurrence of this fact in the shallow peat area
(SP) is thought to cause by the strong influence of the presence of mineral fractions that can infiltrate the structure of the peat matrix so that the finesized soil fraction (mineral and organic) has a more significant proportion than medium peat (MP) and deep peat (DP) area. The mineral fraction that can infiltrate the peat matrix in the SP area comes from minerals carried by the flood swings of the Sabangau river, where the SP area is right on the Sabangau river edge. It is also due to the mineral ground's influence under the peat layer, which is $<100 \mathrm{~cm}$ from the ground surface.

Relation of bulk density, particle density, and porosity shown in Figure 3. The bulk density parameter used to determine its relationship with the total pores is dry bulk density, because this parameter is not used in calculating the total pore value directly. In contrast, the wet bulk density parameter is used directly in calculating the total pore parameter value, so of course, the pattern of the relationship can be predictable in advance. The purpose of knowing the relationship between these two parameters is to determine the trend of changes in total pore value when there is a change in peat volume, which in this case is represented by the dry bulk density parameter.

Table 6. Bulk density $\left(\rho_{b}=\mathrm{g} \mathrm{cm}^{-3}\right)$, particle density $\left(\rho_{(s)}=\mathrm{g} \mathrm{cm}^{-3}\right)$ and total pore $(\phi=\%)$.

\begin{tabular}{ccccccccc}
\hline \multirow{2}{*}{ Sample code } & \multicolumn{3}{c}{ Surface layer $(\mathrm{L}-1=0-50 \mathrm{~cm})$} & \multicolumn{3}{c}{ Subsurface layer $(\mathrm{L}-2=50-100 \mathrm{~cm})$} \\
\cline { 2 - 8 } & $\rho_{\mathrm{b}(\text { wet })}$ & $\rho_{b(\mathrm{dry})}$ & $\rho_{(\mathrm{s})}$ & $\phi$ & $\rho_{(\text {wet })}$ & $\rho_{b(\mathrm{dry})}$ & $\rho_{(\mathrm{s})}$ & $\phi$ \\
\hline SP-1 & 0.094 & 0.22 & 0.67 & 84.67 & 0.127 & 0.26 & 0.77 & 83.53 \\
MP-1 & 0.087 & 0.18 & 0.64 & 86.47 & 0.107 & 0.20 & 0.66 & 83.71 \\
MP-2 & 0.084 & 0.20 & 0.61 & 86.32 & 0.094 & 0.16 & 0.64 & 85.41 \\
DP-1 & 0.087 & 0.14 & 0.61 & 85.84 & 0.087 & 0.16 & 0.59 & 85.34 \\
DP-2 & 0.080 & 0.14 & 0.59 & 86.41 & 0.090 & 0.17 & 0.60 & 84.84 \\
DP-3 & 0.070 & 0.13 & 0.63 & 88.87 & 0.087 & 0.16 & 0.59 & 85.17 \\
DP-4 & 0.070 & 0.16 & 0.59 & 87.99 & 0.080 & 0.17 & 0.56 & 85.72 \\
DP-5 & 0.067 & 0.13 & 0.56 & 88.06 & 0.077 & 0.12 & 0.57 & 86.42 \\
DP-6 & 0.074 & 0.13 & 0.58 & 87.23 & 0.087 & 0.14 & 0.59 & 85.24 \\
DP-7 & 0.064 & 0.12 & 0.57 & 88.92 & 0.074 & 0.13 & 0.57 & 87.06 \\
DP-8 & 0.074 & 0.12 & 0.53 & 85.83 & 0.080 & 0.10 & 0.57 & 90.83 \\
DP-9 & 0.074 & 0.13 & 0.57 & 87.02 & 0.067 & 0.11 & 0.54 & 86.94 \\
DP-10 & 0.090 & 0.11 & 0.55 & 83.61 & 0.074 & 0.12 & 0.54 & 86.37 \\
\hline
\end{tabular}


Figure 3 showing that total pores value (f) for surface layer $(\mathrm{L}-1=0-50 \mathrm{~cm})$ and subsurface layer $(\mathrm{L}-2=50-100 \mathrm{~cm})$ tends to decrease when increasing the dry bulk density and particle density, however that has low coefficient value $(\mathrm{R}=0.624$ for $r_{b(\text { dry })}$ and $R=0.375$ for $r_{s}$. This fact seems to confirm a directly proportional relationship between parameters bulk and particle density with total pores, even though the bulk density parameter used is dry bulk density, which is not used directly in calculating the total pore parameter.

Porosity describes as volume space filled by water or air in the peat matrix. It depends on the structure of the fraction in the peat matrix formation. Bulk density is a parameter that describes the undisturbed solid mass structure of the peat matrix, and inside there is pores space.

The compressibility of peat is controlled by its physical properties, including its pores' structure and arrangement (Kennedy and Price 2005). Therefore, the particle density parameter describes the amount of solid mass in the peat matrix volume, and inside there is without pore space. In other words, the mass of solids per unit volume of solids (Weindorf and Wittie 2003). The porosity of soil depends on several factors, including (1) packing density, (2) the breadth of the particle size distribution, (3) the shape of particles, and (4) cementing (Ninmo 2004). Although these two parameters describe the same object, namely the mass solids of the peat matrix, the difference between there agree and the amount of pore space mentioned pore total $(\% \mathrm{v})$, consequently, a comparison that parameters are in line (Figure 4). The peat surface layer has a regression coefficient

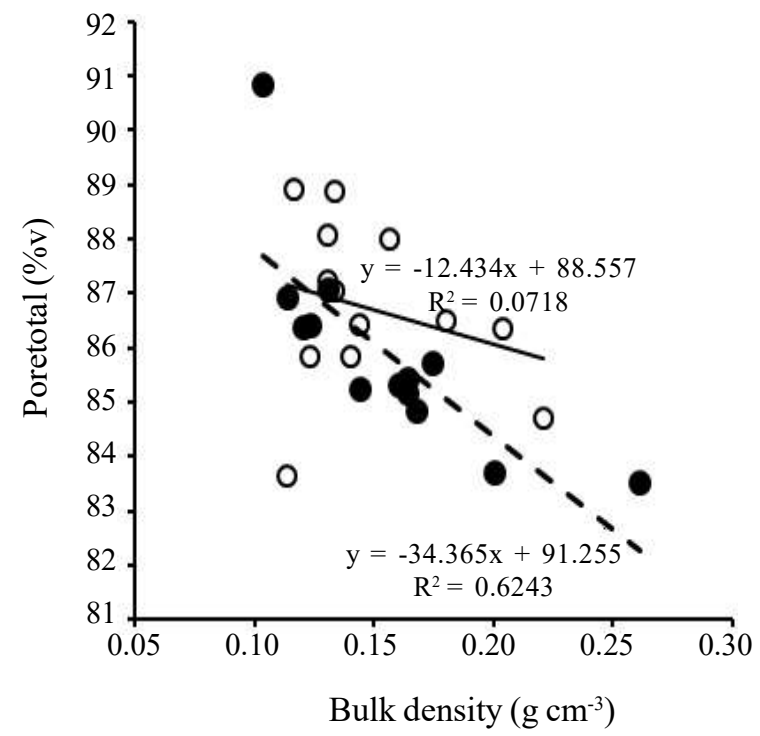

(R) that is 0.814 higher than the subsurface layer $(\mathrm{R}=0.594)$. For subsurface, the low of $\mathrm{R}(<0,75)$ indicates that an increase of solid mass volume does not always follow an increase in the amount of solid mass.

Its inconsistency might be related to the physically dynamic of peat material nearly ground surface (under peat layer deposit), particularly its porosity behavior, e.g., pore structure and its arrangement. Peat material near the ground surface has both elastic and plastic properties that enable it to expand and contract readily with wetting and drying (Boelter 1965). Porosity is often conceptually partitioned into two components, most commonly called textural and structural porosity. The textural component is the value the porosity would have if the particles' arrangement were random, as described above, for granular material without cementing. The textural porosity might be about 0.3 in a granular medium (Ninmo 2004). The structural component represents nonrandom structural influences, including macropores, and is arithmetically defined as the difference between the textural porosity and the total porosity. A research conclusion that the physical properties (bulk density, total porosity, water retention, differential water capacity) of peat depend to no small extent on the relation between their organic and mineral parts (Boelter 1965, Schwärzel et al. 2002, Schwärzel et al. 2006 and Walczak et al. 2002).

\section{CONCLUSIONS}

The relation of bulk and particle density with porosity was a weak tendency, although the porosity

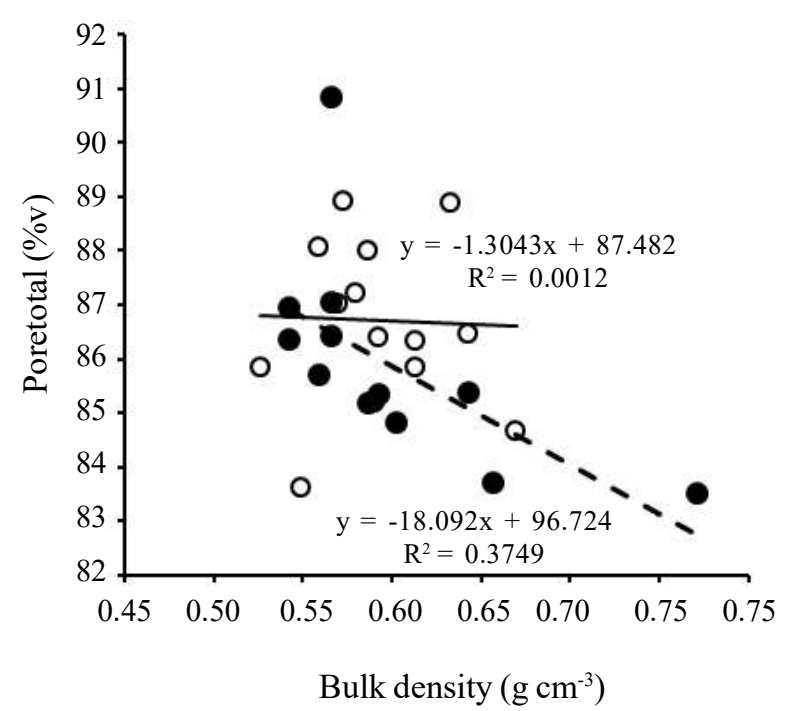

Figure 3. Relation bulk density $\left(\mathrm{r}_{\mathrm{b}(\text { wet }}\right)$ dan particle density $\left(\mathrm{r}_{\mathrm{s}}\right)$ with total pores (f). $\bullet: 50-100 \mathrm{~cm}$ layer, $\mathbf{o}$ : $0-50 \mathrm{~cm}$ layer. 


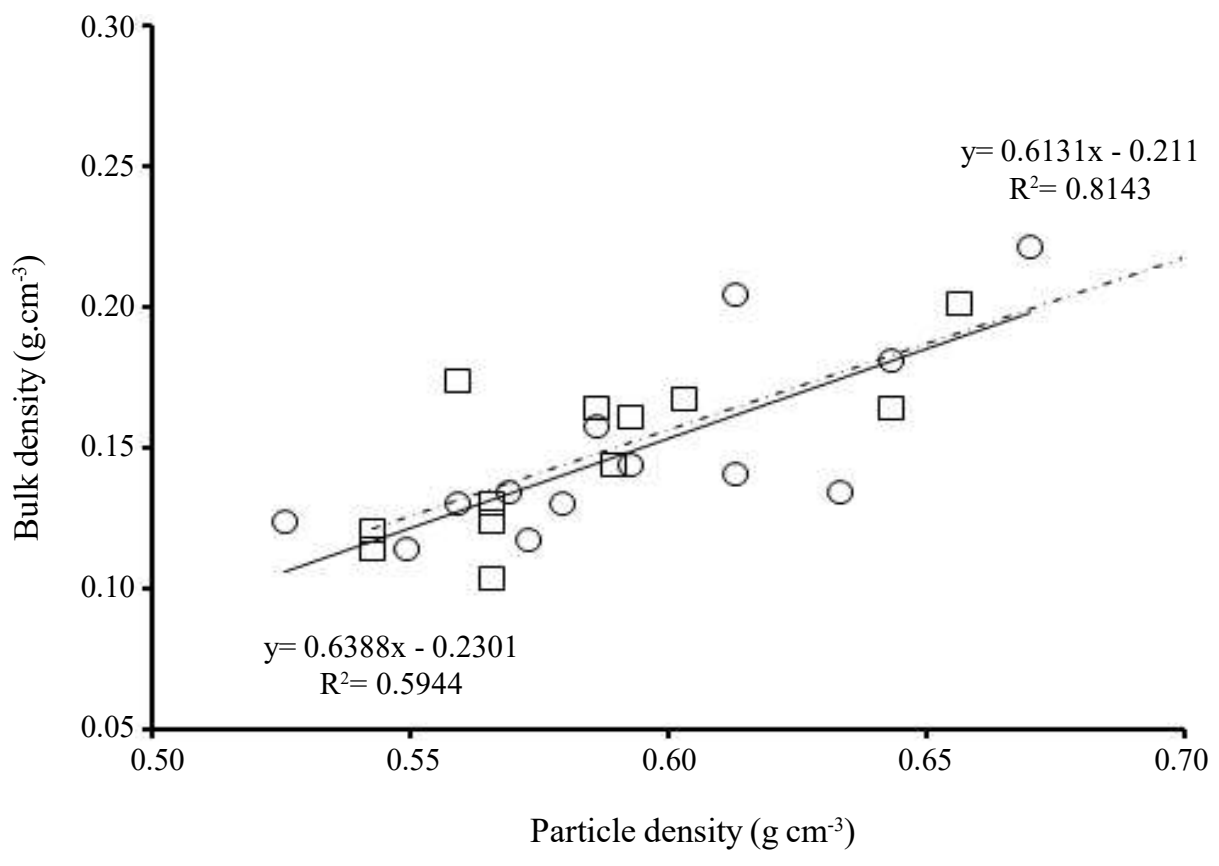

Figure 4. Relation bulk density and particle density. $\bullet: 0-50 \mathrm{~cm}$ layer, $\square: 50-100 \mathrm{~cm}$ layer.

trend to decrease while increasing the bulk and particle density has a low coefficient $(\mathrm{R}=0.624$ for $\mathrm{BD}$ and $\mathrm{R}=0.375$ for $\mathrm{PD})$. The compressibility of peat is controlled by its physical properties, including its pores' structure and arrangement.

The peat matrix's volumetric moisture matrix has the same trend for three-peat thickness categories; were shallow peat, medium peat, and deep peat. Shallow peat moisture levels always appear to be higher than medium peat and deep peat, and this occurs both for the top surface peat layer $(0-50 \mathrm{~cm})$ and for the subsurface peat layer $(50-$ $100 \mathrm{~cm})$. It may be related to soil mineral materials' solubility in the peat matrix, which is supported by the peat layer's presence that coincides with the mineral layer in the ground.

For all peat thickness categories and separate peat layer, the moisture content at $\mathrm{pF} 4.2$ is less than $20 \%$ by volume, and at $\mathrm{pF} 0$ is a maximum of $86 \%$ by volume. The first phenomenon shows that when there is a driving force to release water from the peat matrix equal to a pressure of $15 \mathrm{~atm}$, less than $20 \%$ of the volume of the peat matrix still filled water. The two phenomena show that when the power of water release from the peat matrix is equal to a pressure of nearly $0 \mathrm{~atm}$ (in a flooded field) or saturated, a maximum of $86 \%$ of the peat matrix volume is filled by water.

The saturated degree of shallow peat at the level $\mathrm{pF} \geq 1$ ( $\mathrm{pF} 1-\mathrm{pF}$ 4.2) consistently high compared to the medium peat and deep peat, both at the surface layer $(0-50 \mathrm{~cm})$ and subsurface layer $(50-100 \mathrm{~cm})$. While at $\mathrm{pF} 0$, it is always lower than that of medium peat and deep peat. For all peat thickness categories, the saturated degree at the surface is not significantly different from the subsurface layer.

\section{ACKNOWLEDGEMENTS}

The first author would like to express his gratitude to the supervisors during his Ph.D. Program at Gadjah Mada University, Prof. (em). Dr. Ir. Bostang Radjagukguk and (late) Prof. Dr. Ir. KMRT Tedjoyuwono Hadikusumo, for all directions and guidance during education.

\section{REFERENCES}

Anderson JAR. 1983. The tropical peats swamps of Malaysia. In: Gore AJV (ed) Ecosystems of the world: mires: swamp, bog, fen and moor. Vol. 4B. Regional studies. Elsevier, New York. pp. 181-199.

Badv K and MR Faridfard. 2005. Laboratory determination of water retention and diffusion coefficient in unsaturated sand. Water Air Soil Poll 161: 25-38.

Blake GR and Hartge KH. 1986. Bulk density. In: A Klute (ed.). Methods of soil analysis. Part 1. Physical and mineralogical methods. American Society of Agronomy/ Soil Science Society of America, Madison, Wisconsin, USA. pp. 363-375.

Boelter DH. 1965. Hydraulic conductivity of peats. Soil Sci 100: 606-609.

Campos JRR, AC Silva, JSC Fernandes, MM Ferreira and DV Silva. 2011. Water retention in a peatland with organic matter in different decomposition stages. $R$ Bras Ci Solo 35: 1217-1227. 
Heiskanen J. 1992. Comparison of three methods for determining the particle density of soil with liquid pycnometers. Commun Soil Sci Plant Anal 23: 841-846.

Hillel D. 1982. Introduction to soil physics. Academic Press, New York. 392 p. ISBN: 9780080918693.

Indahyani S, B Sumawinata and Darmawan. 2017. Pengukuran retensi air tanah gambut menggunakan kombinasi three phase meter dan ceramic plate. Buletin Tanah dan Lahan 1: 109-114. (in Indonesian). Jayakody KPK, T Shimaoka, T Komiya and P Ehler. 2014. Laboratory Determination of Water Retention Characteristics and Pore size Distribution in Simulated MSW Landfill Under Settlement. Int J Environ Res 8: 79-84.

Johari NN, I Bakar, SNM Razali and N Wahab. 2016. Fiber Effects on Compressibility of Peat. IOP Conf Ser: Mater Sci Eng 136. 012036.

Kanzari S, MM Hachicha and R Bouhlila. 2012. Laboratory Method for Estimating Soil Water Retention Properties of Unsaturated Soil. Walailak J Sci Tech 9:361-367.

Kennedy GW and JS Price. 2005. A conceptual model of volume-change controls on the hydrology of cutover peats. J Hydrol 302: 13-27.

Könönen M, J Jauhiainen, R Laiho, K Kusin and H Vasander. 2015. Physical and chemical properties of tropical peat under stabilized land uses. Mires Peat 16:1-13.

Kutilek M and V Novak. 1998. Exchange of water in the soil-plant-atmosphere system. Int Agrophysics 12: 33-36

Lal R and MK Shukla. 2004. Principles of Soil Physics. Books in Soils, Plants, and the Environment Series. Marcel Dekker Incorporated. New York. doi:10.4324/ 9780203021231

Lampela M, J Jauhiainen, I Kämäri, M Koskinen, T Tanhuanpää, A Valkeapää and H Vasander. 2016. Ground surface microtopography and vegetation patterns in a tropical peat swamp forest. Catena 139: 127-136.

Letts MG, NT Roulet, NT Comer, MR Skarupa and DL Verseghy. 2000. Parametrization of peatland hydraulic properties for the Canadian land surface scheme. Atmosphere-Ocean 38: 141-160, doi: 10.1080/ 07055900.2000.9649643.

Madi R, GH de Rooij, H Mielenz and J Mai. 2018. Parametric soil water retention models: a critical evaluation of expressions for the full moisture range. Hydrol Earth Syst Sci 22: 1193-1219.

Mualem Y. 1976. Anew model for predicting the hydraulic conductivity of unsaturated porous media. $\mathrm{Wa}$ ter Resour Res 12: 513-522.

Muhammad NZ and JO Rieley. 2002. Management of tropical peatlands in Indonesia: mega reclamation project in Central Kalimantan. In: JO Rieley and SE Page and B Setiadi (eds). Peatlands for People: Natural Resource Functions and Sustainable Management. Proc. of the Inter. Symposium on Tropical Peatland.
BPPT and Indonesian Peat Association, pp. 155-167. Ninmo JR. 2004. Porosity and pores size distribution. In: Hillel D (ed.). Encyclopedia of Soils in the Environment. Elsevier. London, pp. 295-303.

Okruszko J. 1993. Transformation of fen-peat under the impact of drainage. Zesz Probl Post Nauk Roln 406: 3-74.

Page SE, JO Rieley and R W?st. 2006. Lowland tropical peatland of Southeast Asia. In: Martini P, A MartinezCortizas and W Cheswort (eds). Peatlands: Evolution and record of environmental and climate changes. Dev. in earth surface processes series. Elsevier, pp 145-172.

Quinton WL, T Elliot, JS Price, F Rezanezhad and R Heck. 2009. Measuring physical and hydraulic properties of peat from X-ray tomography. Geoderma 153: 269-277.

Quinton WL, M Hayashi and SK Carey. 2008. Peat hydraulic conductivity in cold regions and its relation to pore size and geometry. Hydrol Process 22: 2829-2837.

Radjagukguk B. 1995. Peat soil of Indonesia: location, classification, and problems for sustainability. In: Rieley JO and SE Page (eds). Biodiversity and Sustainability of Tropical Peatlands. Proc. of the Int. Symp. on Biodiversity, Environmental Importance of Trop. Peat and Peatlands Samara Publ. UK. pp 45-54.

Rajkai K, S Kabos and MTh van Genuchten. 2004. Estimating the water retention curve from soil properties: comparison of linear, nonlinear and concomitant variable methods. Soil Till Res 79: 145-152.

Redding TE, KD Hannam, SA Quideau and KJ Devito. 2005. Particle density of aspen, spruce, and pine forest floors in Alberta, Canada. Soil Sci Soc Am J 69: 1503-1506.

Rezanezhad F, JS Price and JR Craig. 2012. The effects of dual-porosity on transport and retardation in peat: a laboratory experiment. Can J Soil Sci 92: 723-732.

Rezanezhad F, JS Price, WL Quinton, B Lennartz, T Milojevic and PV Cappellen. 2016. Structure of peat soil and implication for water storage, flow and sloute transport: A review update for geochemist. Chem Geol 429: 75-84.

Rezanezhad F, WL Quinton, JS Price, D Elrick, T Elliot and R Heck. 2009. Examining the effect of pore size distribution and shape on ?ow through unsaturated peat using computed tomography. Hydrol Earth Syst Sci 13: 1993-2002.

Rezanezhad F, WLQuinton, JS Price, D Elrick, T Elliot and KR Shook. 2010. In?uence of pore size and geometry on peat unsaturated hydraulic conductivity computed from 3D computed tomography image analysis. Hydrol Process 24: 2983-2994.

Rieley JO and SE Page. 2005. Wise Use of Tropical peatlands Alterra - Wageningen University and Research Centre, the Netherlands.

Ritzema HP, AM Mat Hassan and RP Moens. 1998. A New approach to water management of tropical peatlands: A case study from Malaysia. Irrig Drain Syst 12: 123-139. 
Schwärzel K, M Renger, R Sauerbrey and G Wessolek. 2002. Soil physical characteristic of peat soil. J Plant Nutr Soil Sci 165: 479-486.

Schwärzel K, Simunek J, Stoffregen H, Wessolek G, van Genuchten M.Th. 2006. Estimation of the unsaturated hydraulic conductivity of peat soils: Laboratory versus field data. Vadose Zone J 5: 628-664.

Seki K. 2007. SWRC fit - a nonlinear fitting program with a water retention curve for soils having unimodal and bimodal pore structure. Hydrol Earth Syst Sci Discuss 4: 407-437.

Sutikno S, R Rinaldi, E Saputra, M Kusairi, BH Saharjo and EI Putra. 2020. Water management for hydrological restoration and fire prevention in tropical peatland. IOP Conf Ser: Mater Sci Eng 933: 012053. doi:10.1088/1757-899X/933/1/012053.

van Genuchten MT and PJ Wierenga. 1976. Mass transfer studies in sorbing porous media: 1. Analytical solutions. Soil Sci Soc Am J 40: 373-480.

van Genuchten MT. 1980. A closed-form equation for predicting the hydraulic conductivity of unsaturated soils. Soil Sci Soc Am J 44: 892-898.

Vernay M, M Morvan and P Breul. 2016. Influence of saturation degree and role of suction in unsaturated soils behavior: application and liquefaction. E3S Web Conf 9: 14002. doi: 10.1051/e3sconf/20160914002
Walczak R, E Rovdan and B Witkowska-Walczak. 2002. Water retention characteristics of peat and sand mixtures. Int Agrophysics 16: 161-165.

Walker RH, BJ Firkine and PE Brown. 1931. The Measurement of the Degree of Saturation of Soils with Bases. Research Bulletin. No 139. Agronomy section soils. Agri.Experiment Station. IOWA State College of Agriculture and Mechanic Arts.

Weindorf DC and R Wittie. 2003. Determining particle density in dairy manure compost. Tex J Agr Nat Res 16:60-63.

Weiss R, J Alm, R Laiho and J Laine. 1998. Modeling moisture retention in peat soils. Soil Sci Soc Am J 62:305-313

Widjaya-Adhi IPG. 1992. Development of deep tropical peatland for perennial crops. Proc Int Symp on Trop Peatland. Kuching Malaysia, pp. 380-384.

Wösten JHM and HP Ritzema. 2001. "Land and water management options for peatland development in Sarawak, Malaysia. Int Peat J 11: 59-66.

Wösten JHM, E Clymans, SE Page, JO Rieley and SH Limin. 2008. Peat-water interrelationships in a tropical peatland ecosystem in Southeast Asia. Catena 73:212-224. 